This PDF is a selection from a published volume from the National Bureau of Economic Research

Volume Title: A New Architecture for the U.S. National Accounts

Volume Author/Editor: Dale W. Jorgenson, J. Steven Landefeld, and William D. Nordhaus, editors

Volume Publisher: University of Chicago Press

Volume ISBN: 0-226-41084-6

Volume URL: http://www.nber.org/books/jorg06-1

Conference Date: April 16-17, 2004

Publication Date: May 2006

Title: A Framework for Nonmarket Accounting Author: Katharine G. Abraham, Christopher Mackie

URL: http://www.nber.org/chapters/c0136 


\title{
A Framework for Nonmarket Accounting
}

\author{
Katharine G. Abraham and Christopher Mackie
}

\subsection{Introduction and Motivation}

Since their earliest construction for the United States by Simon Kuznets in the 1930s (Kuznets 1934), concerns have been voiced that the National Income and Product Accounts (NIPAs) are incomplete. The NIPAs meet rigorous standards and enjoy broad acceptance among data users interested in tracking economic activity. They are, however, primarily market based and, by design, shed little light on production in the home or in other nonmarket situations. Further, even where activity is organized in markets, important aspects of that activity may be omitted from the NIPAs. In other cases, unpaid time inputs and associated outputs are critical to production processes but, because no market transaction is associated with their provision, they are not reflected in the accounts. One illustration is provided by estimates (LaPlante, Harrington, and Kang 2002) suggesting that the

Katharine G. Abraham is a professor of survey methodology and adjunct professor of economics at the University of Maryland and a research associate of the National Bureau of Economic Research. Christopher Mackie is a staff economist and senior study director with the Committee on National Statistics, National Academy of Sciences.

This chapter reflects the work of a National Academy of Sciences panel study on the design of nonmarket accounts. Katharine G. Abraham served as chair of the panel, and Christopher Mackie was the staff study director. The other members of the panel were David Cutler, Nancy Folbre, Barbara Fraumeni, Robert E. Hall, Daniel S. Hamermesh, Alan Krueger, Robert Michael, Henry M. Peskin, Matthew D. Shapiro, and Burton A. Weisbrod. The panel's final report recently has been published (Abraham and Mackie 2005). Although the listed authors have taken responsibility for drafting the present paper, the ideas it contains reflect the intellectual contributions of all the panel members. The paper also has benefited from the thoughtful comments of Joseph Beaulieu, William Nordhaus, Marshall Reinsdorf, participants in the Conference on Research in Income and Wealth (CRIW) Architecture for the National Accounts Conference, and two anonymous referees. Any flaws in the paper should, of course, be attributed to the listed authors. 
value of in-home long-term care services provided by family and friends is greater than the value of similar market-provided services.

In other areas, the output resulting from market-based production may be incorrectly characterized or valued. There is wide agreement, for example, that the output of the education sector properly should be considered investment rather than consumption, and that its value should be assessed in terms of the returns on that investment rather than the cost of the inputs used in its production. The conventional accounts do not include the asset value of human capital production associated with education, health care and other personal investment activities. Available estimates are rough, but suggest that the value of the human capital stock may be as large as that of the physical capital stock (see Kendrick 1976, and, for a discussion in the context of analyzing economic growth, Mankiw, Romer, and Weil 1992).

Although the importance of nonmarket-but productive-endeavors has long been recognized, few attempts have been made to provide systematic information about even the most quantitatively significant of them. The state of nonmarket accounting today resembles the situation for market-based accounting in the 1920s and 1930s before the creation of the NIPAs. Economic accounting need not, and should not, extend to all nonmarket activities, but there are certain areas in which nonmarket accounts, designed to supplement the NIPAs, could make particularly important contributions. We stress the potential value of new methods of accounting for volunteer and home production efforts, education, health, and environmental improvement or degradation. The raw data pertaining to these nonmarket activities are becoming richer; it remains to be seen whether they can be effectively exploited to expand the nation's accounting of productive activities.

Extending the nation's accounting systems to better incorporate nonmarket production promises substantial benefits to policymakers and researchers. For example, researchers studying the topic of economic growth have long had to supplement data from the national accounts with external estimates of the contributions of research and development, investments in human capital, and the services of the natural environment. Economists and historians have shown that, over the last few centuries of human history, factors such as technical change, scientific inventions, and discoveries in medicine - many of which are nonmarket in characterhave accounted for a very large portion of the growth in living standards. Historical trends reveal the reality that neither economic production nor contributions to social welfare take place exclusively within the market's border, but extend to many nonmarket activities.

Thus, one objective of improved nonmarket accounting is to support alternative aggregate measures of economic performance. Nonmarket accounts would enhance the ability of researchers (and the statistical agen- 
cies) to produce augmented gross domestic product (GDP) statistics and to construct appropriate price deflators needed for real output and productivity measurement. A fuller accounting of national production might lead to different conclusions regarding the level of output today relative to some earlier period, or in the United States compared with another nation.

Nonmarket accounting also would illuminate the processes whereby inputs are transformed into outputs in particular sectors. Consider, for example, the production of health. In contrast to currently constructed health expenditure accounts, which track market payments but do not identify the outputs in a way that is useful for measuring price change or productivity, a health account would relate health improvements - the real "good" that is produced - to medical treatments, as well as to a wide range of other inputs, including diet, the environment, exercise, and research and development. By most measures, improvements in health have outpaced increases in spending on medical care. Since medical care interacts with these interrelated factors, however, we do not know with any certainty the productivity of resources directed toward health care (Cutler and Richardson 1997; Cutler 2004). Optimally, expenditures and outcomes would be tracked so that changes in well-being associated with different actions could be monitored; in turn, this information could support better management of expenditures (both private and public) to achieve desired outcomes.

To take another example, education accounts might be designed to relate improvements in skill capital - the output - to the various inputs to the educational process. As in the health case, schooling is characterized by a mix of market and nonmarket inputs and outputs. The value of time students spend in school - the key nonmarket input — is likely to be at least comparable to the expenditures on marketed inputs. The 2003 Statistical Abstract shows that, in 2000, school expenditures on primary and secondary education amounted to approximately $\$ 400$ billion and that just over 47 million students were enrolled in primary and secondary schools. Assuming 180 days at six hours a day, plus an hour of commuting time and two hours of homework per student, students in these grades devoted more than 75 billion hours to their education. If students' time were valued at the current minimum wage of $\$ 5.15$ per hour (purely for illustrative purposes), the value of unpaid student time would be almost as large as the expenditures measured in the conventional accounts.

The inherent limitation of the NIPAs - that they fail to consider the full array of the economy's productive inputs and outputs - might be less important if market and nonmarket activities trended similarly, but there is little evidence to suggest that they do. To take one frequently cited example, failing to account for the output produced within households may lead to misleading comparisons of economywide production, as conventionally measured. According to Bureau of Labor Statistics (BLS) figures, the female labor force participation rate in the United States has grown 
substantially, from about 34 percent in 1950 to almost 60 percent in 2000 (see http://www.bls.gov). To the extent that the entry of women into paid employment has reduced effort devoted to household production, the long-term trend in output as measured by GDP may exaggerate the true growth in national output (Landefeld and McCulla 2000). Similarly, the relatively smaller portion of total output attributable to home production in the United States as compared to many developing countries surely exaggerates its national output relative to theirs.

Perhaps less well recognized are potential problems with the measurement of national output over the business cycle. If people who lose their jobs during cyclical downturns take advantage of their absence from paid employment to increase the effort they devote to home production, the shortterm decline in national output may be dampened relative to that measured by GDP. Knowing more about the level and distribution of nonmarket activity could be important for other purposes as well. Such information could, for example, change perceptions of the extent of economic inequality among U.S. households and how that has changed over time. This, in turn, could affect where welfare and poverty lines are drawn (Michael 1996).

This chapter identifies and discusses several of the key and sometimes controversial issues hinted at above relating to nonmarket accounting. One goal of this chapter is simply to remind readers of the major omissions built into our system of economic measurement. In so doing, we hope to encourage contributions by social scientists to improve the measurement of nonmarket activity and to point out new ideas and new data sources that have improved the prospects for progress. Time is the dominant input to nonmarket production, and the lack of good measures of how people spend their time has seriously handicapped work in this area. We are optimistic that the newly developed American Time Use Survey (ATUS), produced by the BLS, will spur new work to develop informative nonmarket accounts. Even a cursory glance at the first published statistics from this survey makes clear the potential importance of such an accounting - in 2003, averaging over both employed and nonemployed people, Americans age fifteen and older spent just 3.7 hours per day in market work and work-related activities, meaning that most of their time was devoted to nonmarket activities of one sort and another.

\subsection{Satellite Accounts}

When considering nonmarket economic activity, it is useful to think in terms of satellite accounts that report, on an experimental basis, data on selected activities not covered in conventional accounts. The core accounts have the virtues of consistency over time, hard-won comparability across countries, and solid grounding in observed market transactions. These are strong arguments for maintaining the core accounts in more or less their 
current form. Satellite accounts would not replace the current national accounts, but exist alongside them. They can link to the national income accounts as appropriate, but also expand into areas that the NIPAs do not cover. Further, satellite accounts can be developed, even where standards of accuracy and data quality are not up to the level of the NIPAs, without compromising the conceptual basis or technical integrity of the conventional accounts. Similarly, where no consensus yet exists regarding the best way to measure a particular aspect of nonmarket activity, satellite accounts permit experimentation with alternative methodologies. The goal is to extend the accounting of the nation's productive inputs and outputs, thereby providing a framework for examining the production functions of some difficult-to-measure nonmarket activities.

The idea of satellite accounts is not a new one. The Bureau of Economic Analysis (BEA) long has conducted research on topics beyond the scope of the conventional accounts. A representative BEA description of the role to be played by satellite accounts is as follows:

[S]atellite accounts are frameworks designed to expand the analytical capacity of the economic accounts without overburdening them with detail or interfering with their general purpose orientation. Satellite accounts, which are meant to supplement, rather than replace, the existing accounts, organize information in an internally consistent way that suits the particular analytical focus at hand, while maintaining links to the existing accounts. In their most flexible application, they may use definitions and classifications that differ from those in the existing accounts. ... In addition, satellite accounts typically add detail or other information, including nonmonetary information, about a particular aspect of the economy. (Bureau of Economic Analysis 1994, p. 41)

The United Nations System of National Accounts (SNA) offers a similar description:

Satellite accounts provide a framework linked to the central accounts and which enables attention to be focused on a certain field or aspect of economic and social life in the context of national accounts; common examples are satellite accounts for the environment, or tourism, or unpaid household work. ... Satellite accounts or systems generally stress the need to expand the analytical capacity of national accounting for selected areas of social concern in a flexible manner, without overburdening or disrupting the central system. (United Nations et al. 1993, Glossary, p. 45, and p. 489)

The accounting frameworks described in this chapter generally are harmonious with these definitions. For a number of industries and sectors with significant nonmarket components, satellite accounts hold promise for generating meaningful and useful data to inform policy and to advance research.

In considering the feasibility of nonmarket accounts, it is natural to ask 
how accurate and reliable measures of the relevant inputs and outputs must be in order for the construction of a nonmarket account to be worthwhile. Traditionally, the statistical agencies responsible for economic accounting - the BEA and the BLS - have set high standards of accuracy. The application of similarly rigorous standards to the production of satellite accounts is unrealistic given the inherent limitations of the underlying data. This does not mean that official statistical agencies should eschew nonmarket accounting efforts, but does imply that distinctions should be drawn between the core accounts, together with other major economic indicators, and more experimental efforts to account for important areas of nonmarket activity. Academic and private researchers may be willing to push further in their efforts to account for nonmarket activity than the official statistical agencies. The results of such private research efforts might be analogous to the monthly GDP figures currently published by a private consulting firm, using data supplied by the BEA. The BEA does not consider the data to be sufficiently reliable in all sectors to produce an official version of monthly GDP; even recognizing these data limitations, the consulting firm believes its clients will find the monthly estimates of interest and has decided to produce them. ${ }^{1}$ We anticipate similar situations arising with nonmarket data.

\subsection{Priorities for Expanded Measurement}

\subsubsection{The Scope of Coverage in the NIPAs}

Modern national accounts include primarily goods and services that are bought and sold in market transactions. ${ }^{2}$ The earliest national accounting effort was William Petty's 1665 attempt to estimate England's national income. ${ }^{3}$ By modern standards, Petty's accounts, albeit based on fragmentary data, were fairly wide in scope, covering purchases in the market and imputed values for household production (Kendrick 1970, p. 285). Far narrower were the concepts of the French physiocrats, who believed that only agriculture produced a true net product, or of Adam Smith and Karl Marx, who believed that a country's productive capacity was reflected in its ability to produce material goods, excluding services.

Beginning with the writings of Alfred Marshall (1920) and A. C. Pigou (1920), the trend, in terms of a conceptual objective, was to widen the cov-

1. The business cycle dating committee of the National Bureau of Economic Research is among those making use of the monthly estimates.

2. There are many sources that provide detailed description of the components of the NIPAs and of how they are constructed. For an introduction, see Popkin (2000); further details are available on the BEA website.

3. The historical development of national income accounts has been surveyed by Kendrick (1970). 
erage of national accounts to include all activities that generate "utility" or welfare, including those that take place beyond the market. Pigou wrote that national accounts should include elements that reflect economic welfare and that can "be brought directly or indirectly into relation with the measuring rod of money" (Pigou 1920, p. 11). He emphasized that the word "can" might mean anything from "can easily" to "can with mild straining" to "can with violent straining." National accounting practices in most countries lean far more toward those elements that "can easily" be measured in money terms than those that can be measured only with "violent straining."

It is important to point out that the national accounts produced by the BEA include some activities that do not involve a market transaction or produce a marketed output. Almost 15 percent of GDP (\$1,559.4 billion of $\$ 10,480.8$ billion in 2002) is imputed (see National Income and Product Accounts Table 7.12, Imputations in the National Income and Product Accounts, available at www.bea.gov). The most quantitatively significant imputation is that for the rental value of owner-occupied housing. That this imputation is based on assumptions that are approximately as crude as those for, say, valuing the time spent cleaning a house at the price a cleaning service would charge, suggests that the delineation between included and excluded activities is not purely the by-product of practical considerations. One reason for making an imputation for the value of owneroccupied housing is to ensure that the accounts are invariant to trends in home ownership (which has increased significantly in the past halfcentury). In a similar way, nonmarket accounts could improve our ability to assess trends in total output when the population shifts from unpaid or home production to market substitutes, or vice versa.

Imputations are made for other nonpriced, nonmarketed items in the NIPAs, including wages and salaries paid in kind, food and fuel consumed on farms, and the services provided by banks, insurance companies, and other financial intermediaries that are not reflected in explicit service charges. The imputations for banking services are somewhat unique. In banking, there are observable market transactions that provide an estimate of the nominal value of banking output. Imputations are necessary, however, to allocate the nominal value of unpriced services between borrowers and depositors (see Fixler, Reinsdorf, and Smith 2003, for a more complete discussion).

One key characteristic of the nonmarketed items that are covered in conventional accounting systems is that their consumption is very closely related to the sales and purchases of marketed goods and services, making the estimation reasonably straightforward. For some nonmarket items, the imputation process would be far more difficult, although these distinctions are a matter of degree. If the term "imputation" refers to any data that are not directly observable, then it is clearly the case that the development of 
nearly all national accounting data, whether market, near market, or nonmarket, involves some degree of imputation.

Finally, information relevant to many areas of nonmarket activity already is included in the national accounts. Purchases of inputs that contribute to nonmarket production often are treated as expenditures for final demand. This is true, for example, in the case of household production; spending on food, cleaning supplies, and household appliances all are counted as part of personal consumption. ${ }^{4}$ Some of the costs borne by government and parents for children's education are included in the accounts but not the value of the time students devote to their education (on the input side), and there is no attempt to measure directly the value of the resulting human capital (on the output side). Similarly, many of the inputs to medical care are included in the accounts, but unpaid inputs of time that individuals devote to caring for themselves or family members are excluded, and the accounts shed relatively little light on the value of the health services provided or the health capital formed.

For most areas of nonmarket economic activity that merit further exploration, the accounts do not reflect the full range of inputs used in the production of the output of interest. And in no case is the value of the resulting output, whether goods and services produced for current consumption or the creation of a productive asset, measured fully and independently of the value of the inputs used in its production.

\subsubsection{The Scope of Satellite Accounts}

An overarching question for the architecture of nonmarket accounting is scope - where in the range of activities that could be deemed to have economic value to draw the border of inclusion. Nonmarket accounts would extend coverage of productive inputs and outputs to facets of the nation's economy that are largely nonmarket in character, but they should not include all human activities; the idea of producing an overall summary measure of total human satisfaction is futuristic at best. Instead, priority should be given to the development of experimental accounts for those areas that most closely resemble the activities represented in conventional market accounts. These experimental accounts would provide a framework for examining the production functions of some difficult to measure activities not covered - or not adequately covered - in the NIPAs. Initial work should address omissions in output measurement, somewhat narrowly defined, which implies setting a boundary that excludes activities (such as leisure or sleep) for which "prices" would be difficult, even in prin-

4. Conceptually, it would be preferable to treat household consumer durables (such as most appliances) as capital assets since, like other capital goods, they deliver a flow of productive service over time. The fact that the BEA does not treat home production as being within the production boundary for the NIPAs is a barrier to their being treated in this fashion in the conventional accounts. 
ciple, to derive from market comparisons. Additionally, the focus should be on areas where improved accounting would contribute to policymaking and science.

Satellite accounts augment information in the market-oriented economic accounts to provide a more complete picture of economic activity in key nonmarket areas. This allows the existing NIPAs, including the headline GDP measure, to continue to be constructed in a historically consistent manner. At the same time, data from mature satellite accounts could be used by researchers to construct alternative-concept measures of output or welfare. The principal reasons for having national accounts are to be able to monitor trends in the economy and to forecast the impact of alternative policy choices. This implies that satellite accounts, like the NIPAs themselves, will be most valuable to research and policy if they are produced on a regular schedule.

A wide range of productive activities are worthy of exploration for possible inclusion in a set of augmented accounts. Among the areas of top priority, we would include measurement of

- Household production

- Investments in formal education and the resulting stock of skill capital

- Investments in health and the resulting stock of health capital

- Selected activities of the nonprofit and government sectors

- Environmental assets and services

We highlight these areas for satellite accounts for several reasons, but stress that they do not represent an exhaustive set of potential accounts. Each is substantial in magnitude, so focusing attention on it should improve our understanding of the nation's total production. Several of these areas overlap the NIPAs and thus complement existing official statistics. The list of sectors also reflects a feasibility constraint. Though the construction of almost any nonmarket satellite account is likely to require controversial decisions, the list above excludes areas for which sensible approaches to quantifying and valuing inputs or outputs appear especially far from reach. We also would prioritize areas for which emerging data sources offer new opportunities.

Even within the set of areas identified here, there are differences in readiness to begin the development of new satellite accounts. At this time, accounts for household production and the environment would rest on the firmest foundations; indeed, both the BEA and other national statistical offices already have done substantial work in these areas. In the remaining areas for which we advocate development efforts - the government and nonprofit sectors, education, and health-more extensive basic research and new data collection are needed.

While we acknowledge that nonmarket production extends far beyond what we outline here, a set of accounts that included the five areas listed 
would go a long way toward documenting nonmarket production that contributes to social or private well-being, and would address most of the key principles generalizable to nonmarket accounting broadly. ${ }^{5}$ Other areas of nonmarket activity are quantitatively significant and deserve further attention but, because of data limitations or the lack of a well-developed conceptual framework, are not currently good candidates for inclusion in a coordinated nonmarket accounting initiative. The component of household production associated with the creation of children and the stock of human capital these children embody is a good example. This nonmarket activity obviously has huge economic (and noneconomic) value, but defining, estimating and cataloguing the corresponding prices and quantities in an accounting framework would require knowledge we do not currently possess. Similarly, with the right kinds of data, one might envision accounting for changes in the social environment (e.g. crime and security) that affect living standards in a manner analogous to that used in satellite accounts for the physical environment. At present, however, we do not have the information that would be required to support such an account. There are important scientific and policy questions associated with underground economic production; much of this activity, however, involves market transactions, albeit illegal ones, and thus raises a rather different set of issues and challenges.

Change in the amount of leisure enjoyed by a population is also an important indicator of living standards. Fogel (1999) estimates that the average male household head enjoyed an increase in residual time for leisure activities from 1.8 hours per day in 1880 to about 5.8 hours per day in 1995 . Undoubtedly the aggregate value of leisure in society is high, and could in principle be measured, but in accord with the guiding principle (articulated by William Nordhaus in chap. 3 of this volume) that "nonmarket goods and services should be treated as if they were produced and consumed as market activities ... [and their value] imputed on the basis of the comparable market goods and services," we would recommend against committing resources to the development of a separate leisure account at this time. If the purpose of nonmarket accounts is to "include activities that are economic in nature and those that substitute for market activities" and to begin gradually expanding measurement of the society's economic output beyond that which is covered in conventional economic accounts, then priority should be given to the types of nonmarket activities that involve production in a more traditional sense. Because leisure is such a heterogeneous

5. The recent report of the National Academy of Sciences panel charged with studying the design of nonmarket accounts (Abraham and Mackie 2005) recommends the development of nonmarket satellite accounts for each of the five areas-household production, education, health, the nonprofit and government sectors, and the environment - and makes specific recommendations regarding the measurement and valuation of the relevant inputs and outputs. The report also provides further references to the relevant literature. 
good, and so far removed from any kind of conventionally defined "output," we would recommend focusing attention on aspects of leisure (such as recreation or health-capital-enhancing activities) that may figure into the nonmarket accounting areas identified above.

The question of whether various activities are in scope is also contingent on the accounting objective. If the designers of an account cannot decide whether it is intended to capture changes in economic output or changes in societal welfare, the end product may be conceptually muddled. Indeed, these objectives may imply opposing valuations. The simple example of how to value time spent commuting illustrates the complication. If the goal is to measure "output," one would likely want to include the value of, say, parents' time transporting kids to school and other activities. The market cost of hiring a driver might be used to price this time, though there are other alternatives. As the amount of time driving goes up, so too does the value of this component of household production. Yet, as driving time increases, parents' welfare may actually decrease, as time is taken away from leisure and other utility-generating activities. In this case and many others, measuring output and measuring welfare are separate, though admittedly related, exercises. As a practical matter, we would recommend focusing initial efforts on a more thorough accounting of the nation's economic output.

Account designers also must be conscious of the difficulty of drawing boundaries between various related areas of nonmarket activity. Improved health, for example, may result from better medical care, better education that contributes to sounder decisions about diet and exercise, or improved air and water quality. Identifying the full set of inputs to improved health outcomes is difficult, and some of these inputs also may contribute to other desirable outputs. To take another example, additions to the stock of human capital may flow not only from investment that occurs within the formal education sector, but also from investments that occur within the home and thus might be considered a form of home production. There is no realistic alternative to considering the different areas of nonmarket activity separately, but the need to delineate the interactions and complementarities among these different areas should be recognized as work progresses.

One approach that has been used to define nonmarket output (particularly in household production applications) is Margaret Reid's (1934) third-party criterion: is the output in question something that a person could have hired someone else to produce for him? A limited-scope, consumption-oriented household production account could, with some qualifications, be developed using this criterion. For such an account, meals, clothing services, shelter services, and the custodial component of child care would be considered in scope, but fertility, studying, and exercise would not. Because of its conceptual clarity, it may be useful to construct a limited-scope household production account that conforms to the thirdparty criterion. In other areas, such as education and health (some of which 
is produced in the home), the third-party criterion is clearly inappropriate: someone else cannot engage in the activities required to enhance our cognitive skills or improve our health, but these activities produce valuable albeit nonmarketable capital outputs not adequately reflected in the existing national accounts. Nonmarket public goods, such as environmental services, also would not be captured by the third-party criterion.

Another question is whether the pleasure individuals receive from engaging in home production activities, as distinct from the quantity and value of the time they devote to production, should be included as part of the value of nonmarket production. We argue that it should not. Similarly, we would argue against counting the enjoyment experienced by those who volunteer with nonprofit organizations as a part of nonmarket production. Our view on this subject stems, in part, from a desire for consistency. The traditional accounts include the products and services produced by paid workers, but not the enjoyment they may derive from their employment, and we would preserve that distinction in accounting for home production or the output of the nonprofit sector.

There are also related questions concerning what constitutes an input to nonmarket production. In particular, how should the time devoted to consumption be treated? Enjoying a restaurant meal, for example, requires not only the meal itself, but also the time of the diner who consumes it. Should that time be counted as an input to nonmarket production? Again, we do not believe that valuing time spent in consumption is useful, at least not for the first round of nonmarket accounts; we would focus more narrowly on the quantity and value of time that is an input to the production of identifiable goods and services.

A number of other challenges arise in organizing a set of satellite accounts. Time use, for example, is a key input to nearly all areas of productive activity; specific time-use activities, such as volunteering, also may apply to more than one of the identified sectors. Nonmarket activities can be grouped by producing unit - for example, households, government, nonprofit organizations; alternatively, with some overlap and some omission, they can be thought of by industry - for example, education, health. It would be difficult to cover all major nonmarket areas while staying true to a single (delivery system or industry based) organizing principle. The interesting policy and science questions that arise seem to call for data that may be grouped along different dimensions. A consequence of adopting this approach is, of course, that satellite accounts of the type we envision cannot simply be added up to produce alternative national output or income measures.

\subsection{A Conceptual Framework}

Although nonmarket accounts are experimental, they should not be developed in a manner methodologically isolated from the NIPAs. Using the 
national accounts as the starting point offers several advantages. National accounts have been scrutinized, reflecting extensive research and policy use for many decades; the underlying principles are well tested, and practice shows they can be implemented. Additionally, many of the methodological questions about the augmented accounts have analogues and therefore answers in the national accounts (Nordhaus 2002, p. 3).

The national accounts have proven extraordinarily useful as a vehicle for monitoring and studying the evolution of the economy. They have the intentional restriction, of course, that they do not systematically incorporate nonmarket activity. ${ }^{6}$ Given the heavy reliance of policymakers and others on the existing accounts, together with the interest researchers will have in developing augmented measures of output that are compatible with GDP, any supplemental accounts that are developed will be most useful if the information they contain is as consistent as possible with information in the NIPAs.

What specifically does this imply? The NIPAs rest on a double-entry structure that values outputs independently of inputs, and incorporates measures of quantity and price for both. One of the most important applications of the national accounts is the measurement of productivity growth, which requires these separate measures. The NIPAs use dollar prices as the metric for relative value; value outputs at their marginal rather than their total value; and derive these marginal values wherever possible from observable market transactions. Following these same practices in the nonmarket accounts would facilitate comparisons between them and the NIPAs.

The national accounts report three measures for each type of product at the most detailed level: the quantity, the price, and the dollar value. These are linked by the principle that value is price multiplied by quantity. With few exceptions, the accounts obtain data on value from primary sources, and quantity is calculated by dividing value by a measure of price. In a few cases, data on value and quantity are obtained, and price is calculated as the ratio of the two. We anticipate that similar calculations would be used in satellite accounts. In addition, a satellite account might use data on quantity together with estimates of prices to calculate value as the product of the two. This procedure seldom is necessary in the national accounts, where value generally is available from primary sources.

\subsubsection{Implications of the Double-Entry Bookkeeping Approach}

One of the strengths of the NIPAs is the double-entry bookkeeping used in their construction. Independent estimates of total output are developed

6. As discussed above, the BEA does measure services of owner-occupied housing, food consumed on farms, and certain financial services of banks and insurance companies. The BEA also measures governmental services, though they are currently measured at cost (plus depreciation of capital) and thus, from our point of view, incompletely. Work to improve the BEA's method of measuring government services is currently underway; see Fraumeni and Okubo (2005), which discusses measurement of full government services from capital. 
on the basis of the dollar value of output sales, on one hand, and the dollar value of payments to factors of production, on the other. In principle, these two independently derived sums - the product side and the income side estimates of GDP - should be equal. The difference between the two estimates is the statistical discrepancy, which by construction differs from zero only because of measurement errors. In the conventional accounts, a small statistical discrepancy suggests that the value of output has been well measured, since two independent measurement methods give approximately the same answer; a larger statistical discrepancy signals the existence of measurement problems.

Interpretation of the difference between input costs and output values is somewhat less straightforward in the case of a nonmarket account. In a competitive market context, an inefficient firm - one for which the value of the resources employed exceeds the value of the output produced-eventually will be driven out of business. Competitive pressures do not operate in the same way in the nonmarket context. That households seek to optimize with respect to their allocation of time is a more tenable assumption than the alternatives, but households that fail to optimize are not driven out of business and may continue to exist indefinitely. This introduces the possibility that, depending on how it is measured, the cost of time devoted to home production could exceed or fall short of its productive value.

The conceptual equality of output values and input costs in the market accounts also reflects the convention that is employed for measuring capital costs. Revenues not spent on other costs of production are considered to be a part of the cost of capital; put differently, capital is treated as the residual claimant. An alternative approach to valuing capital servicesand one that seems applicable to the nonmarket accounts - would be to use a standard measure of the flow cost of capital. Using this approach, the cost assigned to capital services could be greater or less than their productive value.

Capital-market constraints, such as those that might arise from lenders' reluctance to finance the production of assets that cannot be marketed and therefore cannot readily serve as loan collateral, may be particularly important in the nonmarket context. Absent capital market constraints, larger investments might be made. Because the amount of investment is constrained, however, the return on investments that do occur will exceed the market rate of return. Valuing nonmarket investments in a fashion that ignores this possibility - for example, valuing educational output based on the costs of the inputs employed - could lead to a figure that is less than the true value of the asset produced.

Differences in technology or scale of production between nonmarket and market production are other possible reasons for divergence between the costs of inputs and the value of output in nonmarket production. It might be more efficient, for example, to prepare ten meals rather than one; 
unless they belong to a large family, however, individuals cooking at home cannot take advantage of this scale economy, and reasonable estimates of the value of resources used to produce the meal at home might exceed the market value of the restaurant meal. The transactions costs associated with traveling to dine at a restaurant, however, might still make it attractive to cook and eat at home.

Though the sum of the values of the inputs used to produce a nonmarket output may provide a poor estimate of the value of that output, this has commonly been the practice for measuring some areas of nonmarket production. It is, for example, by far the most common approach in the literature on the value of government services or of home production (see Slater and David 1998 on the former, and Holloway, Short, and Tamplin 2002 on the latter). Well-designed input-based output valuations are a clear improvement over ignoring nonmarket activity altogether. Only with an independent measure of the value of nonmarket output, however, can one hope to address many of the questions for which nonmarket accounts could be most valuable.

In sum, there is a strong argument for adapting the double-entry bookkeeping of the NIPAs for use in any satellite accounts, even if it is not operationalized in exactly the same way in the nonmarket context. For some areas - especially those such as health, where output measurement is especially difficult - input and output measurement will not develop in tandem. This should not be a deterrent to accounting efforts in these areas - a onesided account is generally better than no account at all. For example, an input-based account for formal education based on imputed values of student time would be useful even if it did not measure the value of the output of education independently. Similarly, an accounting of volunteer labor in the economy could provide useful data for research and policy. Expanded availability of time-use data will advance efforts to identify and quantify productive inputs, and it might provide clues about how to value them.

\subsubsection{Classifying Deliveries as Intermediate Output or Final Demand}

Several efforts to modify or otherwise expand the national accounts have originated from the belief that misclassifications in the present accounts give a false impression of economic activity. For example, one could argue that at least some governmental activities (e.g., protection and inspection services) properly should be treated as inputs to business activity rather than as an output of the economy, as is current practice. ${ }^{7}$ Similarly, commuting costs and other work-related consumer expenditures could be viewed as inputs to production rather than as outputs included in consumption (though it is not obvious how these costs should be assigned for

7. These views, as well as issues of classification more generally, are discussed in Conference on Research in Income and Wealth (1958). 
use in, say, productivity measurement). Conversely, some items now classified as intermediate inputs might better be classified as output for final demand. Researchers at the BEA have recognized this issue and changed the way they classify some market production. For instance, the BEA now classifies computer software purchases by businesses as investment rather than as an intermediate expense.

As with their market counterparts, nonmarket inputs and outputs must be properly classified for use in a double-entry accounting system and to be useful for productivity analysis. Classification of market activities, much less nonmarket ones, is not always easy, but resolution of these classification issues will be a necessary step in the development of an expanded set of accounts.

\subsubsection{Externalities}

It would be extremely useful if satellite accounts included estimates of externalities. In this respect, satellite accounts would differ markedly from the NIPAs. An externality is an effect from the action of one individual or business that either damages or creates a benefit to others with no corresponding compensation paid or received by those who engage in the activity. The treatment of externalities is a particularly important issue for environmental accounting. The most interesting applications relate to air and water pollution, where externalities carry potentially very high values. The value of goods and services that can be produced from environmental resources are clearly linked to changes in the level of pollution; part of the impact of pollution is captured in the market accounts but part is not. A reduction in the amount of particulate emissions, for example, may result in reduced worker absence due to illness (a market effect) but also in (nonpriced) health gains. Likewise, factors affecting the state of the environment may or may not be manifest in market expenditures. The cost of catalytic converters is directly reflected in automobile prices. On the other hand, in choosing its production technology, a firm is unlikely to consider the full costs of pollution associated with different options.

The extent to which the aggregate effects of pollution are captured in the NIPAs depends on who bears the costs. As pointed out by William Nordhaus (chap. 3 in this volume), there are two relevant cases. In the first case, the entire impact of an externality flow is reflected in the market accounts, even though there is no market transaction. If a chemical firm pollutes a nearby water source, and the sole harm that arises from that action is that a farmer's crop yield (sold at market) is reduced, the flow takes place within the market. For accounting purposes, this case is a concern only if we want to disaggregate production accurately by sector-here, chemicals and agriculture. The second case, in which externalities flow across the market boundary, is more problematic. If pollution from the chemical plant affects the quality or quantity of outputs such as nonmarket recreational opportunities or the population's health, then failure to account for these effects 
will distort output and welfare measures. Nordhaus suggests that, to account properly for the second case, standard accounting methods in the NIPAs would need revision since externality disaggregation changes value added in both the nonmarket and the market sectors.

The relevance of this kind of information to policy is fairly obvious. Accounting data on externalities would assist policymakers charged with setting taxes or permit fees for emissions of pollutants or disposal of industrial wastes. If properly set, such taxes and fees will closely approximate the costs of the damage associated with the harmful activity, internalizing the costs and thereby encouraging socially optimal decisions about production processes. But whether or not fees and charges reflect the true positive and negative values of the air and water services provided, such as the positive value of waste disposal services or the negative value of the pollution associated with waste disposal, a society that charges firms for the right to pollute will, by conventional market measures, look different from an otherwise similar society that is laissez-faire regarding externalities.

In an accounting framework, there are two ways to handle environmental improvement or degradation that is tied with market production. We could think of pollution created by a firm in the course of its production of goods as a negatively valued output - the firm is producing goods, but also harmful emissions. We could also think of the pollution-related environmental damage as a cost of production - to produce, the firm needs workers, equipment, and the environment for waste disposal. It should be noted that pollution damage and the input of waste disposal services are not alternative measures of exactly the same thing. In fact, they are usually unequal in dollar terms and, indeed, waste disposal values can be quite high even when pollution damage is near zero, or vice versa. For this reason, environmental accounting systems should keep these concepts distinct. Valuation of degradation, as it affects nonmarket outputs (e.g., health and recreation), is difficult because the link between pollution and health is not well understood, and because valuing health increments is controversial. Nonetheless, development of such valuations clearly would have broad applications. ${ }^{8}$

\subsubsection{Measuring Quantities}

Dollar values are relatively easy to obtain for the market inputs to nonmarket production. Quantity measures for these market inputs can be constructed by applying appropriate price deflators to the nominal expenditure data. In contrast, for both nonmarket inputs and nonmarket outputs, quantity measurement often will be a necessary first step in the development of monetary valuations.

Even in the case of market inputs, complications arise. Purchases of cap-

8. Further discussion of environmental accounting issues can be found in Nordhaus and Kokkelenberg (1999). 
ital equipment by households, for example, are treated as purchases for final consumption in the NIPAs. But measuring the inputs to household production requires a measure of the stock of consumer durables. To create such a stock estimate, one must combine information on spending over time for dishwashers, refrigerators, vacuum cleaners, washing machines, and other capital equipment used in home production with information on these items' useful lives. Although there are practical difficulties that complicate estimation of the stock of capital equipment used in home production, the basic approach is well developed. ${ }^{9}$

An especially important nonmarket input on which, until very recently, quantity data have been lacking is the time devoted to nonmarket production. Fortunately, the American Time Use Survey (ATUS), launched at the start of 2003 by the BLS, should go a long way toward filling this gap. The ATUS, described a bit more fully below, can be expected to provide good data on the time inputs for a range of productive household activities. These data would be even more useful if the Census Bureau were to produce regularly updated information on the distribution of demographic characteristics in the population, designed to complement the new information on time use and to support accounting efforts generally. A complete demographics database might include information on the age, gender, school enrollment status, years of education and degrees completed, occupation, household structure, immigrant status, employment status, and other characteristics of the population. Knowing about the distribution of demographic characteristics and changes in that distribution over time would, for example, help researchers determine whether observed changes in the pattern of time use reflect changes in population mix or some other factor. The demographic data to support such an effort are, for the most part, already available, largely from the Census Bureau but in some cases from the BLS, the National Center for Health Statistics, and other agencies. A determined researcher could compile these data from existing sources, but it would be very helpful if the information were assembled in a single place, adjusted to be consistent over time. The demographic database would not itself be a satellite to the existing economic accounts, but it would assist in the development and use of such satellite accounts.

The ease with which the quantity of nonmarket outputs can be measured varies widely. Relatively good data are available, for example, on the educational attainment of the working-age population. These data provide a starting point for quantifying the output of the educational sector. Changes in mortality and morbidity are similarly well documented and could provide a basis for quantifying changes in the health status of the

9. This is a case for which the BEA already maintains the desired data series, albeit not as a part of the core accounts. See Katz (1983) for a discussion of measuring the stock of consumer durables. 
population, particularly if combined with information from a demographic account that tracked changes in population mix. In other cases, considerable creativity may be required to measure the quantities of nonmarket outputs, and doing an adequate job ultimately may require the collection of new data. Tracking air quality would require better measures of the pollutants to which the public is exposed and of the costs they impose. Tracking the output of the household sector would require data on such things as meals prepared or loads of laundry washed and dried. But, at least in principle, it is possible to see how this task might be approached.

To elaborate on the laundry example, on the input side, the accounts would tally the number of hours devoted to laundry; these hours could be valued using the wage of a domestic employee or the opportunity cost or predicted market wage of the person doing the laundry (these methods are discussed in the next section). The remaining inputs would be the capital services of the household's washing machine and dryer, together with electricity, water, detergent, and other necessary materials. Both quantities and prices would be reported. On the output side, the accounts would report the amount of laundry done and its price, estimated on the basis of what it would have cost to have the laundry cleaned commercially. ${ }^{10}$

\subsubsection{Assigning Prices}

Anyone contemplating the development of nonmarket accounts must decide how best to value inputs and outputs in the various accounts, given the absence of prices. Valuation typically involves finding market analogues for the nonmarket inputs or outputs in question. Given the distance from the market of some utility-generating activities, however, this approach is not always feasible.

How to measure the value of unpaid time devoted to nonmarket production is the central input valuation question. One possible approach is to value nonmarket time at the opportunity cost of the person performing the nonmarket activity. Another approach employed in the literature has been to value this time at market substitute prices - the wage that would be paid to a person hired to perform the task in question. The two approaches may give quite different answers if higher-wage individuals devote time to tasks for which the market wage is relatively low.

It may, at first blush, seem puzzling why anyone would choose to perform activities that compensate - in the form of either wages paid or value of nonmarket output produced - at a rate below the wage that could be earned in market employment. Further reflection makes clear that such

10. More thought needs to be given to what productivity measures mean when they are based on market replacement valuations. In the absence of direct measures of the output of nonmarket activities, one might impute using information on the relationship of outputs to inputs in market production. In such cases, productivity measures for nonmarket activities may simply recover the imputation scheme. 
decisions may be entirely rational. Economic theory conceives of people making marginal choices about their allocation of time to different activities. At the point of maximum satisfaction, the marginal personal lost value associated with working for pay or to produce a valuable output should be equated to the marginal personal benefit, the wage rate, or, in the case of nonmarket production, the value of the output produced. Personal lost value equals the difference between the marginal satisfaction or enjoyment that could be derived from engaging in nonwork activities and the (presumably lesser) marginal satisfaction or enjoyment intrinsic to the work in question.

A key point in this theory is the following: even at the same moment, the time of any individual may have different marginal values reflected in different rates of compensation. The reason is that different activities may be associated with different amounts of personal lost value. A lawyer who commands $\$ 200$ per hour from corporate clients may do work at $\$ 50$ per hour for a charity. Providing the work to the charity has an offsetting personal benefit (enjoyment) absent from working for a corporation. By the same principle, highly paid individuals may choose to prepare meals at home that could have been purchased in the market at a cost far below the wages the individual could have earned by working for pay instead of cooking. The recreation component of cooking means that the marginal value of the cooking performed is lower than the wage, if there is no similar recreational value in the person's job. In both of the cases - the lawyer performing work for a charity or the highly compensated person cooking meals at home - we would overstate the cost of inputs to nonmarket activities and understate their productivity if we mistakenly used the opportunity cost wage to value the time spent in activities the individual finds enjoyable.

We turn to economic theory for guidance in attaching an appropriate replacement cost value to time spent in nonmarket activities that someone else could have been hired to perform. A production function relates the productive inputs - labor $L$ and capital $K$ - to output $Q$ :

$$
Q=f(b L, K)
$$

Quantitatively, people's time $(L)$ is the most important unmeasured input in nonmarket production. In the nonmarket context, we often must compare an unpaid labor input to a market replacement. People performing nonmarket tasks may be less skilled and work less hard, on average, than people doing similar work in the market for pay. In the production function for nonmarket output, $b$ is a measure of the relative efficiency of nonmarket as compared to market labor. If our speculation is correct, $b$ will typically be a number between zero and 1.0. An appropriate procedure for cases in which a family member performs work at home that could have been performed by someone hired in the market is to count the family 
member's hours as measured and to value those hours at a rate equal to the efficiency factor, $b$, multiplied by the market wage for someone performing the type of work in question. Thus, if a home owner chooses to reroof the house and, using the same materials and tools, takes twice as long to do a comparable job as it would have taken a professional roofer making $\$ 30$ per hour, we would record all of the time the home owner spent on the task and value that time at $\$ 15$ per hour. Further, we would use the same $\$ 15$ per hour valuation whether the home owner earns $\$ 100$ or $\$ 10$ in his or her own market job. In the case of the $\$ 100$ per hour person, we implicitly would be assigning the roofing task an amenity value of $\$ 85$ per hour, while in the case of the $\$ 10$ per hour person, we would be assigning it a disamenity value of $\$ 5$ per hour.

With respect to a task that cannot be given to another person-such as studying or exercising - the appropriate price is the opportunity cost of the time. For people who work in the market, the opportunity cost may reasonably be derived from their wages; some imputation must be made for those not employed in market work. In either case, some adjustment should in principle be made for any difference in the amenities of work activities as compared to nonmarket activities.

Valuing nonmarket outputs often will be even more difficult than valuing inputs. A sensible guiding principle is to treat nonmarket goods and services as if they were produced and consumed in markets. This means that, wherever possible, the prices of nonmarket goods and services should be imputed from a market counterpart. Many youth sports organizations, for example, are operated largely by volunteers. Although a fee may be charged for participation in the activity, that fee cannot be viewed as a market price. But there are also private firms that offer opportunities for children to participate in similar recreational activities that do charge a market-determined price. Given information on the relevant output quantities - for example, numbers of children participating in a nonprofit youth sports organization's various recreational programs - the price charged for participating in similar activities offered by private firms could be used in valuing the nonprofit organization's output.

In some cases, there may be differences in quality between homeproduced outputs and market outputs, just as there may be between home and market production inputs. In principle, the valuation of nonmarket outputs should take into account any differences in the quality of those outputs as compared to similar market outputs, much as we proposed for the valuation of nonmarket as compared to market labor inputs.

Even in the case of near-market goods, market and nonmarket outputs may be imperfect substitutes, complicating comparisons of their value. More difficult yet are the cases in which a nonmarket good is an asset that has no direct market counterpart and is never sold. A possible approach in these cases may be to use market prices to value the stream of output pro- 
duced by the asset over time and then to treat the present value of the returns as a measure of the asset's value. This approach has a clear grounding in the standard theory that underlies the valuation of marketable capital assets and is the approach taken, for example, by Jorgenson and Fraumeni $(1989,1992)$ in their work on the valuation of investments in human capital. They begin by calculating the increments to earnings associated with successive increments to education. The present value of the earnings increments, cumulated over a person's productive lifetime (and assuming that education enhances the value of market and nonmarket time equally), is then used as a measure of the value of the incremental investment in human capital.

Investments in health also yield a flow of nonmarketed services over time. Improved health increases not only expected years of labor market activity, and thus labor market earnings, but also the expected number of years available in which to enjoy all that makes life rewarding. Developing a market-based measure of the value of additional years of life that may flow from health care investments is controversial, though labor market data have proven useful for this purpose. Specifically, the fact that different occupations are associated both with different risks of fatal injury and with different relative wage rates has been exploited to derive estimates of the value of an additional year of life. Such measures, while far from perfect, have the advantage of being based on real-world decisions that yield observable market outcomes, and for that reason they have appeal.

Different approaches may be necessary for the case of nonmarket outputs that are public in nature, such as crime rates and air quality. Again, however, it may be possible to develop measures of the value of these outputs on the basis of market transactions. The levels of many, if not all, of these nonmarket outputs are likely to differ across localities. People presumably will be willing to pay more to live in communities with low crime rates and good air quality than in communities that lack these attributes. The value of such positive attributes should be reflected in house prices. At least in principle, one could derive an estimate of the value of lower crime rates, better schools, or higher air quality from a hedonic model that relates house prices to these (and other) community characteristics (see Black 1999 for an interesting application).

There are a number of areas for which market valuation, or even imputations based on nonmarket analogues, are simply unavailable and impossible to obtain. Examples of these might include some aspects of social capital, such as family stability; the effect of terrorism on the population's sense of well-being; or the "existence" and "legacy" values of national monuments, such as the Grand Canyon. In these cases, any attempted valuation would have to rely on more indirect evidence. We would argue strongly that attention should be directed first to those categories of non- 
market output for which the most defensible, market-based approaches to valuation are possible.

\subsubsection{Counting and Valuation Issues}

The national accounts have a consistent structure for reporting prices and corresponding quantities. The two have an intimate connection, because prices form the basis for aggregating the quantities of different products. The national accounts have adopted the approach long advocated by index-number theorists - the accounts compute chain-weighted quantity indexes of groups of products by weighting the percent change of the quantity of each product by its share in the dollar value of all the products. As a result, the accounts directly support productivity calculations. Productivity growth for any group of products - including the full complement of products in GDP - is the percent growth of the aggregate quantity less the corresponding weighted growth of the inputs.

In the market economy, monetary aggregates generally are the most accessible measures of the level of activity - dollar values of sales, dollars paid as wages and salaries, and so on - and measuring quantities often is more difficult. By definition, however, nonmarket activity does not involve monetary transactions. This means that the data on monetary aggregates that form the building blocks for traditional national income accounting are simply not available. Instead, available data may consist of physical or other quantity indicators of the level of activity, such as hours of time devoted to home production, student-years of education provided, or ambient concentrations of various air pollutants.

On one side are those who argue that no nonarbitrary way exists for assigning monetary values to a heterogeneous set of nonmarket inputs or outputs, and that any such assignment unavoidably will reflect value judgments that are inappropriate for a statistical agency (see, e.g., van de Ven, Kazemier, and Keuning 2000, p. 8). The counterposition holds that, without an attempt to assign monetary values to the quantity indicators that are the basic unit of measurement for nonmarket outputs, it will be difficult for policymakers to digest and use the information. This may mean that nonmarket outputs end up being ignored, which implicitly assigns them a value of zero. Alternatively, policymakers may assign a value to the nonmarket output using subjective methods that are far less defensible than the methods that would be employed by a statistical agency. In either case, there is a good argument for measurement specialists to provide estimates based on the best possible methods, even if these are highly imperfect, rather than leaving a statistical void. Another argument for attempting to assign monetary values to quantity indicators is that the effort filters out indicators that may be of minor economic importance. One problem with purely physical accounting systems is that, useful as they may be for 
some research topics, they tend to be encyclopedic and difficult to comprehend. Economics can minimize biased value judgments by providing scientific guidelines for approximating prices in many cases. And with a monetary metric, the aggregation of detailed measures of output to larger, useful indexes is possible. For these reasons, nonmarket inputs and outputs should be, to the maximum extent possible, valued in dollar terms.

The usefulness of a monetary valuation approach depends on the extent and accuracy with which monetary values ultimately can be assigned to the inputs and outputs in question. In order that such assignments be as objective as possible, we favor basing these valuations wherever possible on information derived from the terms of observable market transactions or their analogues. And, even when it is difficult to base valuations on market transactions, it is important that valuation methods be reproducible by independent observers. In certain instances, assigning prices to outputs (or inputs) may be so controversial that publishing physical quantity accounts may be the best available option. Given that both price and quantity data are needed to calculate values for the conventional monetized accounts, however, it is reasonable to produce the best price and monetary estimates available, as long as sets of assumptions are clearly stated. Limiting an account to physical quantity reporting should be the exception, not the rule. We also again emphasize the desirability of giving priority to those areas of nonmarket accounting for which it is possible to draw valuations from market comparisons.

\subsubsection{Marginal and Total Valuation}

Economic valuation methods fall into two broad categories: the first, which tracks the framework of the national accounts, relies on prices, which reflect marginal benefits; the second considers the full amount consumers would be willing to pay for a good or service, which includes a consumer surplus to the extent that amount is greater than the price. Thus, the two approaches differ in the way benefits are measured.

In the case of a product or service sold in a competitive market, the price is set at a value that equates the cost of producing and the value of consuming the marginal unit of output. Marginal valuation omits consideration of the inframarginal benefits of goods and services. In many cases, knowing consumers' willingness to pay for first and subsequent units of a good or service does not matter for any decision. Although the public enjoys a large consumer surplus from the production of ice cream-that is, enjoyment exceeding in value the total price paid for the ice cream - there is no policy or accounting issue relating to that surplus. Productivity and other types of measurement use the marginal values revealed by the market price. The same principle applies to many of the nonmarket goods and services that would be included in satellite accounts.

One important area for which the differences between marginal and to- 
tal valuations are likely to be substantial is health care. Imagine a new pill that cured sickle cell anemia and could be produced at a marginal cost of $\$ 1.00$. The total value of that innovation would be enormous; the marginal valuation attached to sales of these pills would be minimal. For a health account, it would be more consistent with accounting principles to think about such cases in terms of the social profit generated by the productive activity. This requires that careful attention be given to the task of identifying and categorizing inputs and outputs. In a fully specified health account, inputs such as basic research and development (R\&D), time spent in health improving activities, medical innovations-some of which are bought and sold in markets and some which are not - enter on one side; on the other (output) side, changes in health status, the valuation of which reflects some estimate of the value of a year of healthy life, must be measured and valued. Because the input and output sides are independently valued, they could, if properly measured, reveal social profits realized from research investments and other inputs. In our example, the value to society of the incremental change in health status associated with finding a cure for sickle cell anemia may well exceed the cost of its development, even taking all of the contributing inputs into account.

The potential for large social profits seems particularly relevant in the case of new products, which bring discrete changes in benefits to consumers. It has been argued that the value consumers place on new products should be reflected in properly constructed price indexes as a decline in the price level (see, for example, Hausman 1996). While there is not yet a consensus on this issue in the price index literature, we would note that deflating nominal expenditures with a price index that accounted for the value realized by the purchasers of new goods would yield an estimate of real output that included consumer surplus associated with the introduction of these goods. It is meaningless, in a national income accounting context, to estimate total value for existing products. Sometimes total value data will be needed for a cost benefit analysis, and this is fine; cost-benefit analysis and national accounts rest on different conceptual ideals and objectives.

\subsection{Data for Nonmarket Accounting}

One barrier to the development of satellite accounts such as we have described in this chapter has been the limitations of the data available to support quantification and valuation of covered activities. As already noted, the new ATUS will provide rich information on the most important input to nonmarket production - the time people devote to nonmarket activities. Other inputs to nonmarket production commonly are purchased in markets, meaning that the challenges associated with measuring these inputs, while not trivial, should be similar in nature to those routinely encountered in the construction of the NIPAs. Considerable work will be required to 
develop the data needed for independent measurement of nonmarket outputs. In this section, we briefly describe the new ATUS, then identify several other key data needs.

The data appropriate to measuring the amount of time devoted to nonmarket activities must necessarily come from recording information on people's activities away from their jobs. The vehicle for collecting such information is a time-budget survey - a study in which a large sample of individuals keeps a diary of their activities over one or several days. In a timebudget survey the activities typically are just listed descriptively together with the time spent on them, then coded into a set of categories. One of the benefits of time-budget surveys as compared to other methods of learning about how people spend their time is that time-budget surveys force the reported aggregate of time devoted to all activities to equal 1,440 minutes per day for each person.

While time use studies have periodically been funded by federal agencies, none has been designed or conducted by any part of the federal statistical system. In January 2003, the BLS began collecting time budgets as part of the monthly ATUS. Researchers and activists interested in valuing women's time in the household were the first to urge that the BLS develop a time use survey, but the data from the new survey, now operational after nearly a decade of development and testing (see Horrigan and Herz 2005), will have much wider applicability in the construction of supplemental economic accounts for the United States.

The ATUS samples are taken randomly from individuals in households that have completed their eighth month of participation in the Current Population Survey (CPS). The BLS had expected to sample roughly 2,800 households per month and to obtain a 70 percent response rate. Due to funding constraints, the number of households sampled has dropped from 2,800 per month to 1,800 per month beginning in January 2004 . The response rate from the diaries taken by telephone has been just 59 percent, while from the small number taken in person (from households without telephones) it has been just 34 percent. Looking forward, actual responses thus are expected from individuals in about 1,200 households each month, with roughly 14,000 individuals expected to complete diaries each year starting in 2004.

Households are chosen based on a variety of stratifications (including race/ethnicity and presence of children of various ages), all designed to reduce the sampling variance of the statistics describing smaller subsets of the U.S. population. A crucial issue for our purposes is the classification of the respondents' verbal descriptions of activities into categories that are useful for accounting and for analysis. The basic codes are aggregated into seventeen top-level categories: Personal Care (mainly sleep); Household Activities; Caring for and Helping Household Members; Caring for and Helping Non-household Members; Work and Work-Related Activities; 
Education; Consumer Purchases (e.g., food shopping); Purchasing Professional and Personal Care Services (e.g., doctors' visits); Purchasing Household Services; Obtaining Government Services and Civic Obligations; Eating and Drinking; Socializing, Relaxing, and Leisure; Sports, Exercise, and Recreation; Religious and Spiritual Activities; Volunteer Activities; Telephone Calls; and Traveling. Within each of these broad categories, there are further disaggregations. The structure of the categories appears to accord well with the construction of supplemental accounts along the lines discussed in this paper. In addition to completing the time use diaries, ATUS respondents update their CPS collected information on work behavior, demographics, earnings and (bracketed) family income.

As a large-scale and ongoing time-budget survey the ATUS is unique worldwide. Several other countries' time-budget data sets are large enough to generate reliable measures of time allocation of the sort needed to construct statistically meaningful snapshots, but no other country has time use data to support supplemental nonmarket accounts that are analogous to the NIPA accounts in being continuously updated. The annual ATUS samples are very large relative to those for other countries' time use surveys, but what makes the ATUS particularly valuable for the purposes of creating nonmarket accounts is that its information will be provided year after year.

The ATUS can be used to quantify time spent by the population in productive activities, both market and nonmarket. Some have argued that the decisions of the ATUS designers to collect only one day's time budget from each respondent and to survey only one member per household limit the value of the ATUS data. It is true that the design of the ATUS makes it less useful for certain kinds of research, such as that focused on the timing of activities or on household bargaining. These features of the survey are not, however, a major drawback when it comes to constructing time use estimates for satellite accounts.

Other aspects of the ATUS design may be more significant for the use of these data in nonmarket accounting. One relevant design feature is that the survey tracks "primary" activities, but not secondary ones; in other words, the data are coded to show people engaged in just one activity at a time. The survey does include separate questions designed to learn about time devoted to child care, which empirically is by far the most important "secondary" activity reported by respondents to other time use surveys. Still, more complete information about secondary activities could prove to be important for monitoring time devoted to productive nonmarket activities that may occur simultaneously with other tasks or pastimes. A related question is whether activities that typically require only a few minutes at a time - for example, putting a load of laundry in the washer, and then later moving it from the washer to the dryer-will be reported consistently enough to support good estimates of time devoted to them. Another limi- 
tation of the ATUS from the nonmarket accounting perspective is that data are collected only for people age fifteen and older. The exclusion of children and young teens means that other data will be needed to quantify the time spent in school or school-related pursuits, as would be required to construct an education satellite account.

Perhaps our major concern about the ATUS is the risk that the data may not be fully representative of how the average person spends his or her time. Although there is no way to know for sure until the data can be carefully examined, it seems plausible that busier individuals might simply be less likely to participate in the survey, meaning that the survey estimates could be distorted. Efforts to assess the extent of any possible bias in the survey responses - and, if necessary, to address that bias by raising response rates or making appropriate adjustments to the estimates-should be a top priority.

These comments are not, we would stress, intended as criticisms of the ATUS, which we believe represents a great leap forward with regard to accounting for the inputs to nonmarket production. We understand that there were good operational reasons for the decisions made in designing the ATUS. There was evidence, for example, that, had the survey been designed to collect time use information from multiple members of responding household on a particular day, survey response rates would have been much lower. Similarly, testing carried out during the survey development period raised serious concern that probing systematically for secondary activities in which respondents might have been engaged would have greatly increased the perceived survey response burden and thus adversely affected response rates. And the BLS is well aware of the potential for nonresponse bias and has planned research to assess its significance. Still, as work proceeds on the ATUS and on time use data collection more generally, the limitations and potential biases in the data currently being collected for nonmarket accounting purposes should be kept in mind.

A time use survey supplies data on the amounts of time that people devote to different tasks. Nonmarket accounting also requires that values (prices) be assigned to these quantity measures. For valuing time devoted to tasks that could have been performed by a third party - such as nonmarket time devoted to home production or to volunteer activities-we have argued for a replacement cost approach. If nonmarket and market labor are similarly skilled and supplied with similar intensity, the market wage paid to people hired to do the type of work in question may be a reasonable estimate of the replacement cost. In other cases, however, there may be a significant difference between the efficiency of nonmarket as compared to market labor, and in these cases observed market wages should be adjusted to account for the relative (in)efficiency of nonmarket labor. At present, however, we lack the information about market and nonmarket production function parameters that would provide an empirical basis for 
making such adjustments. This is another area where research and data development would be welcome.

As noted above, many nonmarket accounting applications also require information on how the demographic structure of the population is changing. Although individual researchers can compile such information through special-purpose tabulations of CPS or Census Bureau microdata, there is at present no frequently updated published source of information describing the population's basic characteristics. A well-coordinated demographic data compilation effort would have obvious value in nonmarket accounting applications - for example, constructing measures of educational attainment for an education satellite account or, in health, for determining whether changes in the observed incidence of a particular disease were attributable to changes in the age distribution of the population or some other cause. Because the raw materials needed to construct a demographic data set designed to support nonmarket accounting already exist, this should be a relatively easy data gap to fill.

In addition to labor inputs, a complete nonmarket account must include values of nonlabor inputs. Thus, for example, a home production account must include data on the capital services, materials, and energy inputs that complement unpaid labor in generating home-produced outputs. Purchases of materials used in home production already are included in the NIPAs, as consumer goods on the production side and as returns to capital, labor, and other inputs on the income side. The NIPAs also include spending on consumer durables such as refrigerators and washing machines, though the annual flow of services associated with the stock of consumer durables need not correspond especially closely on a year-by-year basis with spending on purchases of consumer durables in the same year (see Fraumeni and Okubo 2001). In accounting for household production, it is the flow of services from these durables that is relevant and for which data are required.

Finally, further research and data development are needed to solve ageold questions relating to the proper definition and measurement of output. What are the outputs of the various nonmarket activities? Zvi Griliches once observed that "in many service sectors it is not exactly clear what is being transacted, what is the output, and what services correspond to the payments made to their providers" (Griliches 1992, p. 7). This observation is especially pertinent for many of the areas of interest here which are dominated by services - and difficult services to measure, at that - such as education, health, social services, culture and the arts, and recreation.

The need for development of better measures of nonmarket outputs can be illustrated with reference to education and health. In such difficult-tomeasure sectors, the value of output frequently is set equal to the aggregate value of the inputs used in its production. Accordingly, little is known about growth, quality improvements, or productivity in these sectors. In 
recent years, alternative approaches have been developed for estimating educational output more directly. Examples of these approaches include indicator (e.g., test-score-based) approaches, incremental earnings approaches, and housing value approaches. Similarly, for a health account, data on the population's health status, of the sort now being developed in disease state and health impairment research, hold promise of providing direct measures of the output of the health sector.

\subsection{Conclusion}

In this chapter, we have argued for efforts to develop a systematic accounting of nonmarket activity to complement the existing national income and product accounts. By design, the NIPAs are focused primarily on market activity and largely ignore the production of goods and services that takes place outside the market. Satellite accounts in areas such as home production, investments in education, investments in health, volunteer activity, and environmental improvements or degradation could be of enormous value in providing a more complete picture of economic growth and in promoting a better understanding of the factors that have contributed to that growth.

The existing national economic accounts have proven their value over a long period of use and refinement. Largely for that reason, we favor modeling nonmarket satellite accounting efforts on the existing national economic accounts. This means, among other things, that we favor the preservation of the double-entry bookkeeping approach that is the hallmark of the NIPAs and reliance on market transactions insofar as possible in the valuation of nonmarket inputs and outputs.

A major impediment to the development of nonmarket accounts has been the paucity of data to support their construction. Lack of suitable data undoubtedly will continue to be a constraint, but the new ATUS seems to us to justify a new round of thinking about nonmarket accounting issues. This new survey will supply key data needed to support a useful accounting of the inputs to nonmarket production. We urge researchers to continue the hard work that will be needed to develop sensible measures of the many and varied outputs associated with nonmarket economic activity.

\section{References}

Abraham, Katharine G., and Christopher Mackie, eds. 2005. Beyond the market: Designing nonmarket accounts for the United States. Washington, DC: National Academies Press. 
Black, Sandra E. 1999. Do better schools matter? Parental valuation of elementary education. Quarterly Journal of Economics 114 (May): 577-99.

Bureau of Economic Analysis, U.S. Department of Commerce. 1994. A satellite account for research and development. Survey of Current Business 74 (November): $37-71$.

Cutler, David. 2004. Your money or your life: Strong medicine for America's health care system. New York: Oxford University Press.

Cutler, David, and E. Richardson. 1997. Measuring the health of the United States population. Brookings Papers on Economic Activity, Microeconomics: 217-72.

Conference on Research in Income and Wealth. 1958. A critique of the United States Income and Product Accounts. A report of the National Bureau of Economic Research. Princeton, NJ: Princeton University Press.

Fixler, Dennis J., Marshall B. Reinsdorf, and George M. Smith. 2003. Measuring the services of commercial banks in the NIPAs. Survey of Current Business 83 (9): 33-44.

Fogel, Robert W. 1999. Catching up with the economy. American Economic Review 89 (March): 1-21.

Fraumeni, Barbara, and Sumiye Okubo. 2001. Alternative treatments of consumer durables in the National Accounts. Paper prepared for the BEA Advisory Committee Meeting. 11 May, Washington, DC. Available at http://www.bea.gov/bea/ papers/cdinnipa.pdf.

- 2005. R\&D in the National Income and Product Accounts: A first look at its effect on GDP. In Measuring Capital in the New Economy, ed. Carol Corrado, John Haltiwanger, and Daniel Sichel, 275-316. Chicago: University of Chicago Press.

Griliches, Zvi. 1992. Introduction. In Output measurement in the service sectors, ed. Z. Griliches, 1-22. Chicago: University of Chicago Press.

Hausman, Jerry. 1996. Valuation of new goods under perfect and imperfect competition. In The economics of new goods, ed. T. F. Bresnahan and R. J. Gordon, 209-37. Chicago: University of Chicago Press.

Holloway, Sue, Sandra Short, and Sarah Tamplin. 2002. Household satellite account (experimental) methodology. London: United Kingdom Office for National Statistics. Available at http://www.statistics.gov.uk/hhsa/hhsa/resources/ fileattachments/hhsa.pdf.

Horrigan, Michael, and Diane Herz. 2005. A study in the process of planning, designing and executing a survey program: The BLS American Time-Use Survey. In The economics of time use data, ed. Daniel Hamermesh and Gerard Pfann, 317-50. Amsterdam: North-Holland.

Jorgenson, Dale, and Barbara M. Fraumeni. 1989. Investment in education. Educational Researcher 18 (May): 35-44.

1992. The output of the education sector. In Output measurement in the service sectors, ed. Z. Griliches, 303-38. Chicago: University of Chicago Press.

Katz, Arnold. 1983. Valuing the services of consumer durables. Review of Income and Wealth 29:405-77.

Kendrick, John W. 1970. The historical development of national income accounts. History of Political Economy 11 (Fall): 284-315.

- 1976. The formation and stocks of total capital. New York: Columbia University Press for NBER.

Kuznets, Simon S. 1934. National income 1929-1932. Senate Document no. 124, 73rd Cong., 2nd sess. Washington, DC.

Landefeld, J. Steven, and Stephanie H. McCulla. 2000. Accounting for nonmarket 
household production within a national accounts framework. Review of Income and Wealth 46 (3): 289-307.

LaPlante, M. P., C. Harrington, and T. Kang. 2002. Estimating paid and unpaid hours of personal assistance services in activities of daily living provided to adults living at home. Health Services Research 37 (2): 397-415.

Mankiw, N. Gregory, David Romer, and David N. Weil. 1992. A contribution to the empirics of economic growth. Quarterly Journal of Economics 107 (May): 407-37.

Marshall, Alfred. 1920. Principles of economics: An introductory volume. 8th ed. London: Macmillan.

Michael, Robert. 1996. Money illusion: The importance of household time use in social policy making. Journal of Family and Economic Issues 17 (Winter): 245-60.

Nordhaus, William D. 2002. Principles of national accounting for nonmarket accounts. Draft document prepared for the Panel to Study the Design of Nonmarket Accounts. Yale University, Department of Economics.

Nordhaus, William D., and Edward C. Kokkelenberg, eds. 1999. Nature's numbers: Expanding the national economic accounts to include the environment. Washington, DC: National Academies Press.

Pigou, A. C. 1920. The economics of welfare. London: Macmillan.

Popkin, Joel. 2000. Data watch: The U.S. National Income and Product Accounts. Journal of Economic Perspectives 14 (Spring): 205-13.

Reid, Margaret. 1934. The economics of household production. New York: Wiley.

Slater, Courtenay M., and Martin H. David, eds. 1998. Measuring the government sector of the U.S. accounts. Washington, DC: National Academies Press.

United Nations, Commission of the European Communities, International Monetary Fund, Organisation for Economic Co-operation and Development, and World Bank. 1993. System of national accounts 1993. Series F, no. 2, rev. 4. New York: United Nations.

Van de Ven, Peter, Brugt Kazemier, and Steven Keuning. 2000. Measuring wellbeing with an integrated system of economic and social accounts. Paper presented at the 2000 meeting of the Sienna Group. 22-24 May, Maastrich, the Netherlands. 